\title{
Building Retrofitting using Hierarchical Optimization and Principal Component Analysis
}

\author{
By Andreas Kanarachos * \\ Georgette Kanarachos ${ }^{\dagger}$
}

\begin{abstract}
In view of the needs for optimization (performance, costs) of building retrofitting, several methods have been proposed in the past. These methods are mostly based on multivariate analysis of data and on mathematical optimization methods. However, the complexity of the task reveals the need for further methodological developments. In this paper a new method based on Hierarchical Optimization (HO) and principal component analysis is proposed. Hierarchical optimization is concerned with decision making problems that involve multiple decision makers ordered within a hierarchical structure and has proved already its usefulness. It helps transforming a global optimization problem into a number of local ones, which also consort with engineering knowledge and practice. In this sense a principal component analysis helps greatly the definition of efficient sub-optimization problems. The above methodology is presented in the following and a case study illustrates its usefulness.
\end{abstract}

\section{Introduction}

Building retrofitting implies the choice and combination of operational parameters (e.g. climate, building use, owner requirements, control, etc.) with passive (e.g. building envelop materials, insulation, roofing materials, finishing materials, window types, etc.) and active system components (e.g. heating, air conditioning, cooling, ventilation, alternative energy sources, building management systems, etc.). The numerous design parameters and the design goals such as minimization of the annual primary energy consumption, carbon dioxide emissions and of the costs constitute a multi-parameter and multiobjective optimization problem.

For the solution of this problem several methods have been proposed in the past [1-20], which refer to almost all factors influencing the thermal behavior of a building, including occupant behavior and control and to methods of optimal design. The later are mostly based on multivariate analysis of data and on mathematical optimization methods. In engineering practice these methodologies are many times exceeded and complemented by professional

*Professor, Frederick University, Cyprus.

${ }^{\dagger}$ Frederick University, Cyprus. 
skills, knowledge and experience. Building performance simulation tools, which incorporate the most significant building design parameters and maximize the reliability of future building retrofitting performance predictions, are also used.

However, the complexity of the task reveals the need for further methods. This paper proposes such a further (new) optimization method based on Hierarchical Optimization (HO). HO was initiated by J. Bracken and J.M. McGill [21]. The activities in the field have ever grown lively, both in terms of theoretical developments and terms of the diversity of the applications [22]. The HO method is concerned with decision making problems that involve multiple decision makers ordered within a hierarchical structure and has proved already its usefulness. It helps transforming a global optimization problem into a number of local ones, which also consort with engineering knowledge and practice. In this sense a principal component analysis helps greatly the definition of efficient sub-optimization problems. The above methodology will be presented in the following and a relevant case study illustrates its usefulness.

\section{Hierarchical Optimization and Principal Components}

Newly, a general model for hierarchical optimization has been presented [23] based on the fact that global searching methods solve in general optimization problems by navigating on the surface of a possibly rugged landscape, which is the optimization function. This kind of navigation is not very effective because the property of the landscape at different resolutions can be very different. Therefore hierarchical optimization emphasizes the possibility to provide a basis for resolution control and smoothing of the search space and to introduce continuous memory into search.

This is especially true for the problem under consideration in view of the fact that the design parameters for the retrofitting process are dissimilar with respect to their essence and nature, as shown in the following:

DP 1: Operational parameters (environment, user requirements, thermal comfort, etc.)

DP 2: Aesthetic/geometrical parameters (building shape, orientation, size, transparent and opaque elements, etc.)

DP 3: Passive building parameters (building envelops, materials, insulation, roofing materials, finishing materials, window types, shading systems, etc.).

DP 4: Active building parameters (heating, air conditioning, cooling, ventilation, alternative energy sources)

DP 5: Building thermal control and management systems

In addition, the above parameters are not continuous, which means that it is very difficult to apply a mathematical optimization procedure. Thus the big 
advantage of hierarchical optimization is that it helps to disintegrate or disrupt the global optimization problem into a number of local optimization problems or even in search procedures.

With respect to the problem under consideration hierarchical optimization allows in a first step to decouple the DP 4 and DP 5 parameters from the other. Performance/cost analyses or optimization procedures for the choice of DP 4 and DP 5 will be performed, not simultaneously, but after the thermal needs have been analyzed and optimized. The optimization problem for a retrofitting design is hereafter reduced into a thermal needs minimization problem within the DP 1, DP 2 and DP 3 parameters spectrum.

Considering that the building exists already, it is obvious that the DP 2 parameters are of minor interest. Changes in building shape, orientation, size, etc., can not be considered and energy minimization can be expected mainly through an intelligent choice of the DP 3 but also of the DP 1 parameters. However the DP 1 and DP 3 parameters differ considerably with respect to their importance. For this reason it seems necessary to proceed to a categorization of the parameters according to their importance with the target to define principal components of the energy analysis/optimization problem. In this sense the following statements are made:

Principal Component: Modeling of the Environment (air, ground)

It is well known, that the environment (outside temperatures, solar radiation, wind velocity, humidity, etc.) varies significantly from year to year. For example in Fig. 1 the record high, record low, average high and average low temperatures for Nicosia, Cyprus are displayed. As it may be seen, the differences between the individual temperatures are not negligible.

Figure 1. Temperatures in Nicosia, Cyprus

\begin{tabular}{|c|c|c|c|c|c|c|c|c|c|c|c|c|}
\hline Month & Jan & Feb & Mar & Apr & May & Jun & Jul & Aug & Sep & Oct & Nov & Dec \\
\hline Record high ${ }^{\circ} \mathrm{C}$ (' $\mathrm{F}$ ) & $\begin{array}{l}21.7 \\
(71)\end{array}$ & $\begin{array}{l}22.2 \\
(72)\end{array}$ & $\begin{array}{l}25 \\
\text { (77) }\end{array}$ & $\begin{array}{l}31.7 \\
1891\end{array}$ & $\begin{array}{l}37.8 \\
(100)\end{array}$ & $\begin{array}{l}46.1 \\
(115)\end{array}$ & & $\begin{array}{l}45.6 \\
(114)\end{array}$ & $\frac{988}{1098}$ & $\begin{array}{l}34.4 \\
(94)\end{array}$ & $\begin{array}{l}28.3 \\
(83)\end{array}$ & $\begin{array}{l}22.8 \\
(73)\end{array}$ \\
\hline Average high ${ }^{\circ} \mathrm{C}\left({ }^{\circ} \mathrm{F}\right)$ & $\begin{array}{c}15.3 \\
(59.5)\end{array}$ & $\begin{array}{c}15.9 \\
(60.6)\end{array}$ & \begin{tabular}{|}
18.6 \\
$(65.5)$ \\
\end{tabular} & $\begin{array}{l}24.3 \\
(75.7)\end{array}$ & \begin{tabular}{|l|}
29.5 \\
$(35,1)$
\end{tabular} & $\begin{array}{l}33.9 \\
(93)\end{array}$ & $\begin{array}{l}36.9 \\
(98.4)\end{array}$ & $\begin{array}{r}36.7 \\
(98.1)\end{array}$ & $\begin{array}{r}33.6 \\
92.5\end{array}$ & $\begin{array}{r}28.3 \\
(82.9)\end{array}$ & $\begin{array}{l}21.8 \\
(71.2)\end{array}$ & $\begin{array}{l}17.1 \\
(62.8)\end{array}$ \\
\hline Average low ${ }^{\circ} \mathrm{C}\left({ }^{\circ} \mathrm{F}\right)$ & $\begin{array}{c}5.2 \\
(41.4)\end{array}$ & $\begin{array}{l}5.0 \\
(41)\end{array}$ & $\begin{array}{c}6.4 \\
(43.5)\end{array}$ & $\begin{array}{c}10.1 \\
(50.2)\end{array}$ & $\begin{array}{c}14.5 \\
(58.1)\end{array}$ & $\begin{array}{l}18.8 \\
(65.8)\end{array}$ & $\begin{array}{l}21.8 \\
(71.2)\end{array}$ & $\begin{array}{l}21.6 \\
(70.9)\end{array}$ & $\begin{array}{c}18.5 \\
(65.3)\end{array}$ & $\begin{array}{l}15.0 \\
(59)\end{array}$ & $\begin{array}{c}10.2 \\
(50.4)\end{array}$ & $\begin{array}{c}6.8 \\
(44.2)\end{array}$ \\
\hline Record low ${ }^{\circ} \mathrm{C}\left({ }^{\circ} \mathrm{F}\right)$ & $\begin{array}{l}-4.4 \\
(24)\end{array}$ & $\begin{array}{c}-5 \\
(23)\end{array}$ & $\begin{array}{l}-2.2 \\
(28)\end{array}$ & $\begin{array}{c}1.1 \\
(34)\end{array}$ & $\begin{array}{c}3.9 \\
(39)\end{array}$ & $\begin{array}{l}7.2 \\
(45)\end{array}$ & $\begin{array}{l}8.9 \\
(48)\end{array}$ & $\begin{array}{l}6.7 \\
(44)\end{array}$ & $\begin{array}{c}2.8 \\
(37)\end{array}$ & $\begin{array}{l}-1.1 \\
(30)\end{array}$ & $\begin{array}{l}-3.3 \\
(26)\end{array}$ & $\begin{array}{l}-5.6 \\
(22)\end{array}$ \\
\hline
\end{tabular}

As environment represents the main input of a thermal analysis and it describes the conditions for which a retrofitting solution is sought, different scenarios can be defined. For example:

- Winter scenarios $\mathrm{W}_{\text {Seasonal }}$ for the winter period based or meteorological data of a certain year, considering or neglecting solar radiation. This implies the use of a seasonal or monthly energy analysis method.

- Winter scenarios $W_{\text {Day }}$ for the "coldest" winter day, using either average low or record low temperatures, again considering or 
neglecting solar radiation. This implies the use of a time continuous energy analysis method.

Analogous $\mathrm{S}_{\text {Seasonal }}$ and $\mathrm{S}_{\text {Day }}$ scenarios can be defined for the summer. The choice of a scenario for which the thermal analysis will be performed is therefore of considerable importance. For example the choice of scenario $\mathrm{W}_{\text {Day }}$ postulates that retrofitting should be able to cover thermally the average or record low temperatures in the winter (consequently it can cover thermally all other days) and that these temperatures are also responsible for the dimensioning of the thermal system. The same statement is true for summer. Other scenarios are also possible.

\section{Principal Component: User Needs}

User needs co-define the objective function of retrofitting optimization. If for example there is no need for a continuous $24 \mathrm{~h}$ heating or cooling of the building (or of part of the building), then the retrofitting process has to consider intermittent operation of the thermal system. The choice of a scenario for "user needs" for which the thermal analysis will be performed is therefore of considerable importance. For example discontinuous heating or cooling according to user needs imposes other requirements than other metrics.

Principal Component: Modeling of Passive Building Elements

Passive building elements co-define the thermal flow in the building parts. This makes necessary the use of multilayered wall, roof and floor elements. In such cases one has to choose between e.g. a U-value- or a R-C-dynamicmodeling of the thermal analysis. As energy simulations based on different thermal models lead to different results, the choice and modeling of a "passive building element" is also of considerable importance.

Principal Component: Modeling of the Thermal Process

Parameters that influence the thermal analysis itself, as e.g. the air changes per hour $n$, the inner mass $m_{\text {inner }}$ within a thermal zone, the transient response of the building from an unheated to a heated period, etc., which can not be defined with the desirable accuracy are also considered as principal components. In such cases a sensitivity analysis becomes necessary.

\section{A 2C3R Thermal Zone Model for Retrofitting}

In order to apply the above methodology a 2C3R dynamic analysis model of a building (or generally of a "thermal zone") has been developed (Fig. 2). This model includes:

a. The components of the thermal zone (roof, floor, east, west, north, south walls, inner mass and transparent elements) including geometrical, structural-physical characteristics and boundary conditions 
b. The volume of the air and the ventilation in the zone

c. Shading characteristics of each of the building components

d. Sun radiation to and absorbed radiation of each of the building components

e. Boundary conditions for each of the building components, as e.g. outside air temperature, earth temperature or temperature due to interaction with other buildings or parts of buildings

f. HVAC and internal loads as defined by the user and/or the control system

As already stated, a multilayered modeling of the building components is incorporated. In the present case 5 layers $\mathrm{R} 1-\mathrm{C} 1-\mathrm{R} 2-\mathrm{C} 2-\mathrm{R} 3$ have been foreseen. The layers R1, R2 and R3 represent the outer, between and inner insulation and $\mathrm{C} 1$ and $\mathrm{C} 2$ the thermal masses between $\mathrm{R} 1$ and $\mathrm{R} 2$ and $\mathrm{R} 2$ and R3.

For the implementation of such a 2C3R model for retrofitting purposes, the design engineer has to consider the interior design, the energy needs of each department of the building and also the user behavior and the relevant thermal control. In many cases, specific thermal (and acoustic) insulation becomes necessary inside the building, e.g. in case of separation of the living from the sleeping or working departments of the building.

Figure 2. A Building, Considering Environment, Interior Design, User Behavior and Thermal Control

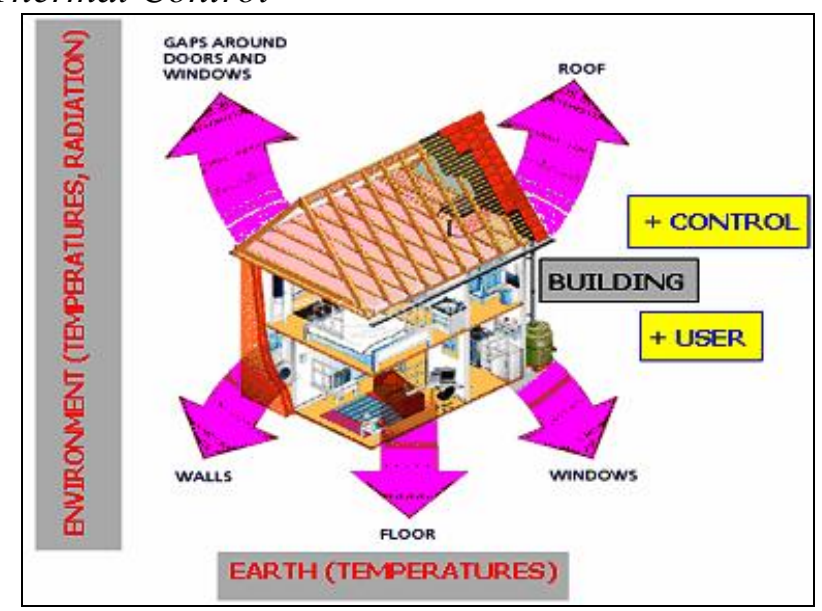

The main characteristics of a $2 \mathrm{C} 3 \mathrm{R}$ building model can be easily seen from a plot diagram as shown in Fig. 3. Figure 3 (left) displays:

- Volumes " $\mathrm{V}_{\mathrm{C} 1+\mathrm{C} 2}$ " in $\mathrm{m}^{3}$ of the thermal masses of the building components in blue. The displayed volumes refer from left to right to roof, to east-west-north-south walls, to floor and to the inner mass of the building.

- Thicknesses " $\mathrm{d}_{\mathrm{R} 1, \mathrm{R} 2, \mathrm{R} 3}$ " in $\mathrm{cm}$ of the insulation of the building components in red. R1 outer, R2 between and R3 inner insulation. 
The insulation R1, R2 and R3 values for each building component are placed to the right of each $\mathrm{V}_{\mathrm{C} 1+\mathrm{C} 2}$ bar. The displayed values show the case of an inner (R3) insulation of $5 \mathrm{~cm}$ thickness for roof and east-west-north-south walls, while the floor and the inner mass possess no insulation.

- Areas "A $\mathrm{A}_{\mathrm{EWNS}}$ " in $\mathrm{m}^{2}$ of the windows (in general of transparent areas) with EWNS denoting: East-West-North-South.+

Figure 3. Main Characteristics of a 2C3R (R1-C1-R2-C2-R3) Building Analysis

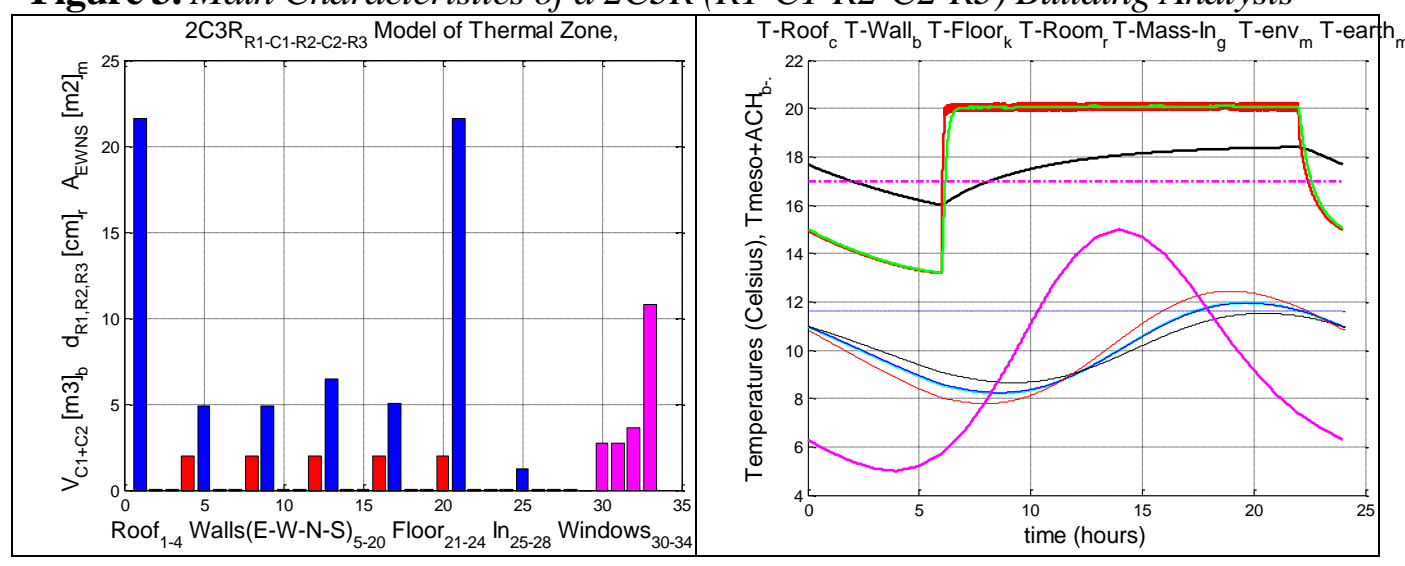

Further, the 2C3R model allows a continuous thermal dynamic simulation as well as its graphical output. The number of the days to be simulated Ds and of the days not to be displayed Dd is user dependent. In Fig.3 (left) the simulation result for $\mathrm{Ds}=10$ and $\mathrm{Dd}=9$ (10 days simulation and display of the results after the 9th day) is shown. In Fig. 3 (right) are displayed in different colors:

- the temperature of the environment (varies between $5^{\circ} \mathrm{C}$ and $15^{\circ} \mathrm{C}$ )

- the earth temperature (constant and equal to $17^{\circ} \mathrm{C}$ ).

- the heating period of the building (between 6:00 and 22:00 hours)

- the set temperature $\left(20^{\circ} \mathrm{C}\right)$

- the air temperature in the building

- the temperatures of the building components and

- the air changes per hour

Separate diagrams display analytically the temperatures of all building components.

\section{A Case Study}

\section{Introductory Remarks}

A free staying residential building in Nicosia, Cyprus (12m (east) x 9m (south) x $3 \mathrm{~m}$ (height)) will be analyzed for retrofitting purposes according to the present method. 
- The building is characterized by an almost negligible insulation of the outer shell, double glazing windows, outside painting with a low absorption coefficient, precautions for minimizing the solar radiation in summer using a shading system and by a high thermal mass: That is $20 \mathrm{~cm}$ thick concrete plates for roof and floor (last in contact with the earth) and $20 \mathrm{~cm}$ thick heavy brick walls, typical for older buildings in Cyprus.

- Only the $\mathrm{W}_{\text {Day }}$ scenario for the winter considering average lowest temperatures $\mathrm{W}_{\text {Day }}\left(T_{\text {Low }}=5^{\circ} \mathrm{C}\right.$ and $\left.T_{\text {High }}=15^{\circ} \mathrm{C}\right)$ and zero solar radiation is, due to limited available space, presented in the following. Other cases follow the same methodology (Principal component: Modeling of the environment (air, ground)).

- The indoor set temperature is $20^{\circ} \mathrm{C}$. The continuous simulation method (time step $=60 \mathrm{sec}$ ) is chosen in order to facilitate introduction of daily patterns, taking also into account control strategies and user behavior (Principal component: User needs).

- The retrofitting process foresees a 3 layers modeling of the building elements as it considers the possibilities of outer or/and inner insulation of the brick walls and roof (Principal component: Modeling of passive building elements).

- Finally, the building is modeled as one thermal zone with internal mass $m_{i}$ and air changes $n$ equal to $n=0$, assuming a common ventilation of its departments in order to facilitate a first order approximation of the thermal process (Principal component: Modeling of the thermal process).

The hierarchical optimization (HO) combined with engineer's knowledge and expertise is applied. It disrupts the global optimization problem into a number of local optimization problems/search procedures (HOSP) HOSP 1 HOSP 5, presented in the following.

HOSP 1: Insulation Scenarios for the Building Shell

In a first step the original (bare) building (Series 1) will be thermally analyzed together with alternative insulation scenarios (Series 2-6), in order to verify the influence of the insulation of the outer shell.

Table 1. Retrofitting Series 2-6

\begin{tabular}{|l|l|}
\hline Series 1 & Building with the existing (nearly zero) insulation \\
\hline Series 2 & Building with inner EPS insulation $5 \mathrm{~cm}$ of walls and roof \\
\hline Series 3 & Building with outer EPS insulation $5 \mathrm{~cm}$ of walls and roof \\
\hline Series 4 & $\begin{array}{l}\text { Building with outer EPS insulation } 5 \mathrm{~cm} \text { and inner EPS insulation } 5 \\
\mathrm{~cm} \text { of walls and roof }\end{array}$ \\
\hline Series 5 & Building with outer EPS insulation $10 \mathrm{~cm}$ of walls and roof \\
\hline Series 6 & $\begin{array}{l}\text { Building with outer EPS insulation } 10 \mathrm{~cm} \text { and inner EPS insulation } \\
5 \mathrm{~cm} \text { of walls and roof }\end{array}$ \\
\hline
\end{tabular}

Simulation results for the Series 1 building for $\mathrm{Ds}=10$ and $\mathrm{Dd}=9$ days ("stationary" response), is shown in Fig. 4 (left). It includes the temperatures of 
the environment and of the earth (magenta), the air temperature in the building (red), the temperature of the inner mass (green), the floor temperature (black) and the temperatures of walls and roof. The mean air temperatures of the building are shown for Series 1 to Series 6 in Fig.4 (right).

Figure 4. Typical Time Response of the Building without Heating (left). Mean Air Temperatures (right)

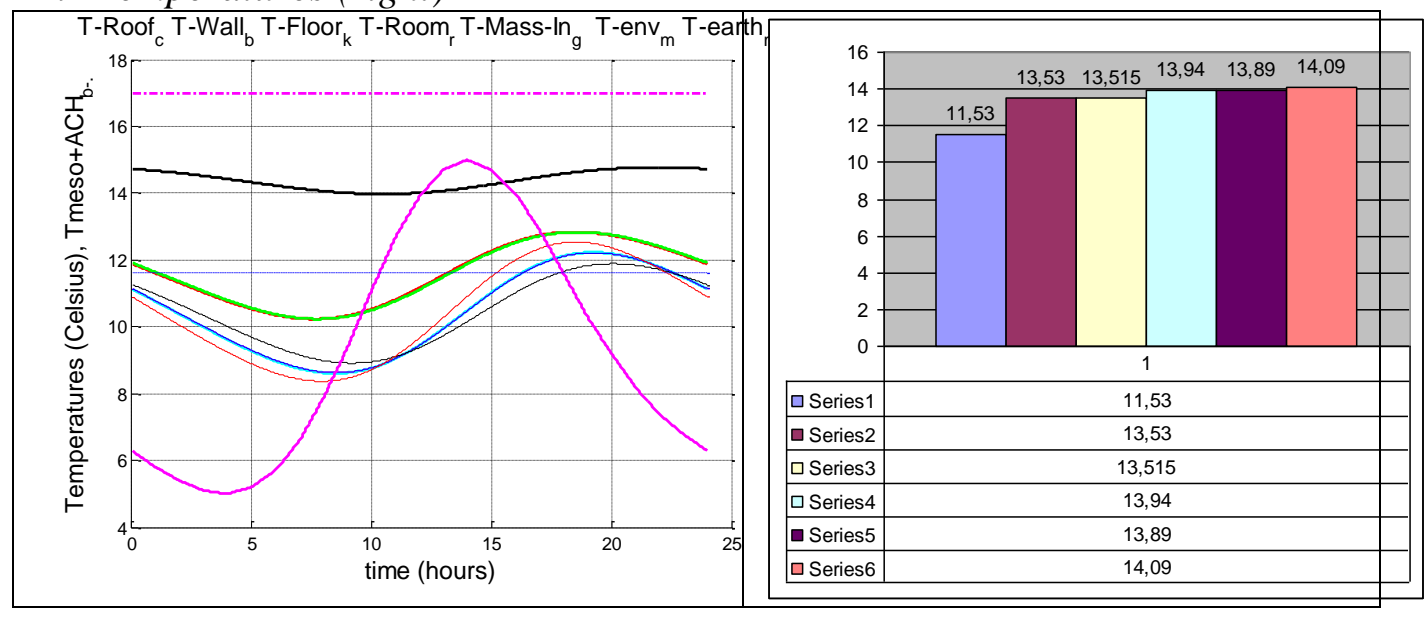

As it may be seen from Fig.4 the room air temperatures differ from the outer air temperature due to the contact of the floor with the earth (earth temperature $17^{\circ} \mathrm{C}$, mean outer air temperature $10^{\circ} \mathrm{C}$ ). The insulation is, as expected, affecting the building air temperature, but this influence diminishes with increasing EPS insulation thickness (Series 4, 5 and 6). Thus, the retrofitting problem consists in compensating the temperature differences of $8,7^{\circ} \mathrm{C}$ and $5,91^{\circ} \mathrm{C}$ for Series 1 and 3 respectively between set and mean temperatures considering state of the art technology but also user needs at a minimum cost.

HOSP 2: Heating Scenarios

Three heating scenarios of the building are investigated (Fig. 5):

1. Scenario 1: Heating 0:00-24:00

2. Scenario 2: Heating 6:00-22:00 and

3. Scenario 3: Discontinuous heating 6:00-8:00, 13:00-16:00 and 19:00-22:00. 
Figure 5. Simulation Results for Heating Scenarios 1-3 for the Series1 Case for a Room Set Temperature of $20^{\circ} \mathrm{C}$
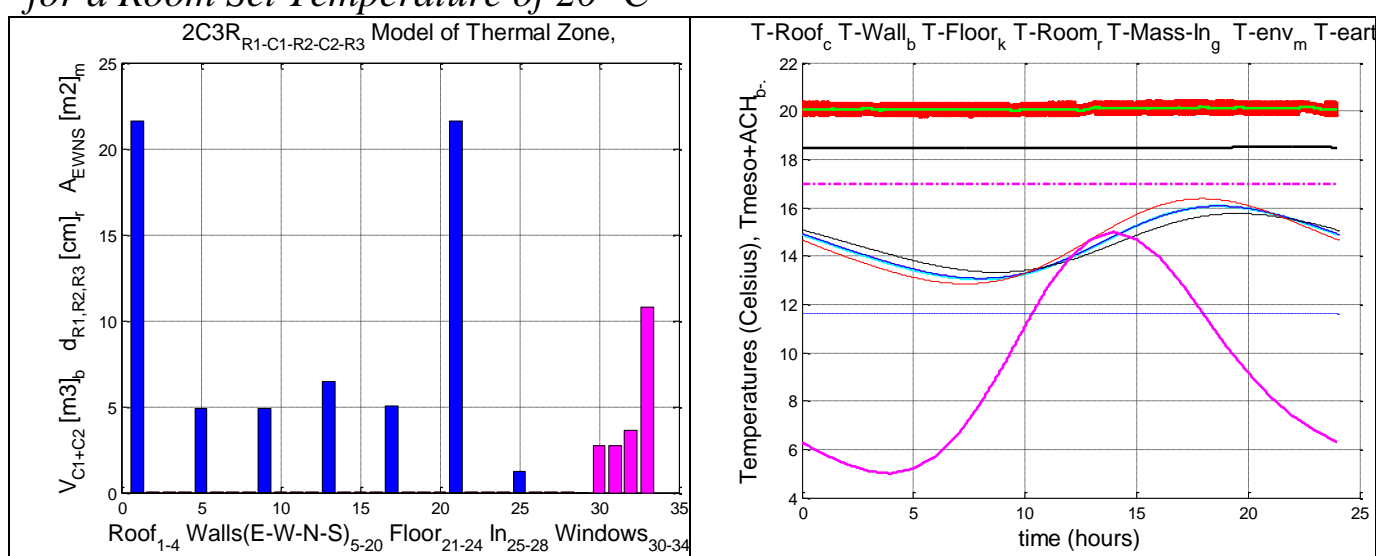

Series 1 case

Scenario 1: Continuous heating 0:0024:00 hours

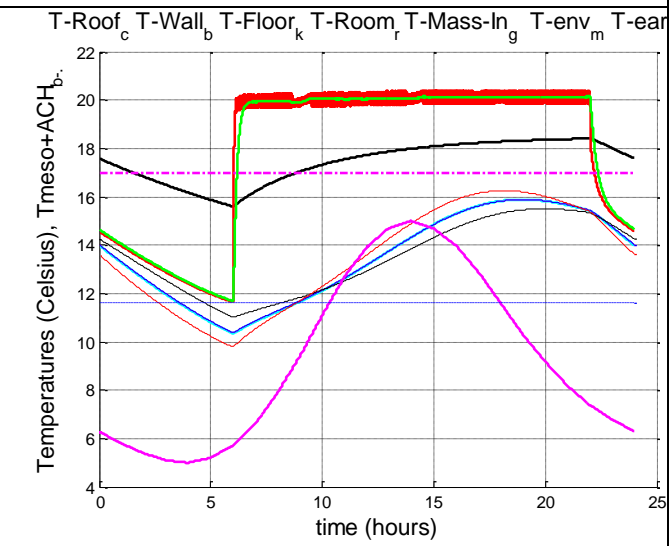

Scenario 2: Day heating 6:00 - 22:0 hours

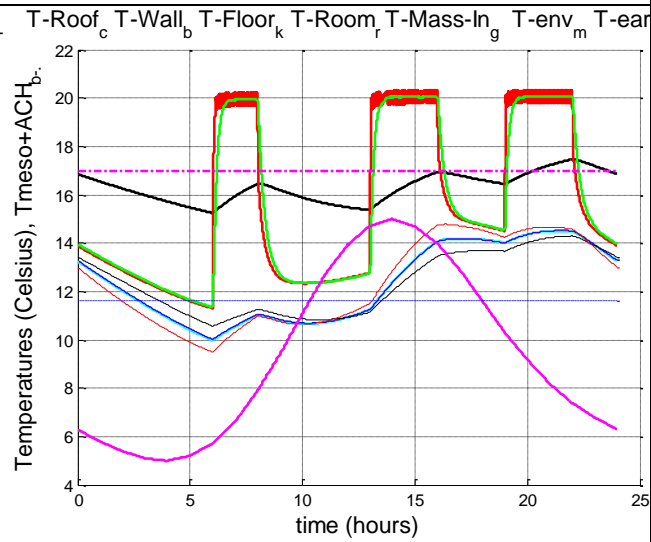

Scenario 3: Discontinuous heating 6:00-8:00, 13:00-16:00 and 19:0022:00 hours

The heating energy per day in KWh needed for realizing the above scenarios is shown in Fig. 6, as percentage of the heating energy needed for Scenario1-Series1.

Fig. 6 shows that energy demand and operational cost depend, as expected, on the user requirements. The monthly (seasonal) method under constant operational conditions (heating 0:00-24:00 under constant conditions e.g. air changes $n$, etc.) represents a maximum with respect to thermal needs (denoted with $100 \%$ ). The heating needs for the not insulated building are reduced if user needs are changed from $100 \%(0.00-24.00)$ to $74.4 \%(6: 00-22: 00)$ and to $46.6 \%$ (discontinuous heating). The same is true also for the other insulation cases. Finally the analysis shows that the inner insulation of the building' shell reduces the heating energy from $100 \%$ to $18.8 \%$, while the outer insulation to $26.5 \%$. The greater reduction of the heating energy in case of inner insulation is due to the smaller thermal mass involved in the heat exchange process in the thermal zone. 
Vol. 1, No. 2 Kanarachos et al: Building Retrofitting using Hierarchical Optimization...

Figure 6. Heating energy per day in \% (Scenariol-Series 1 corresponds to 100\%)

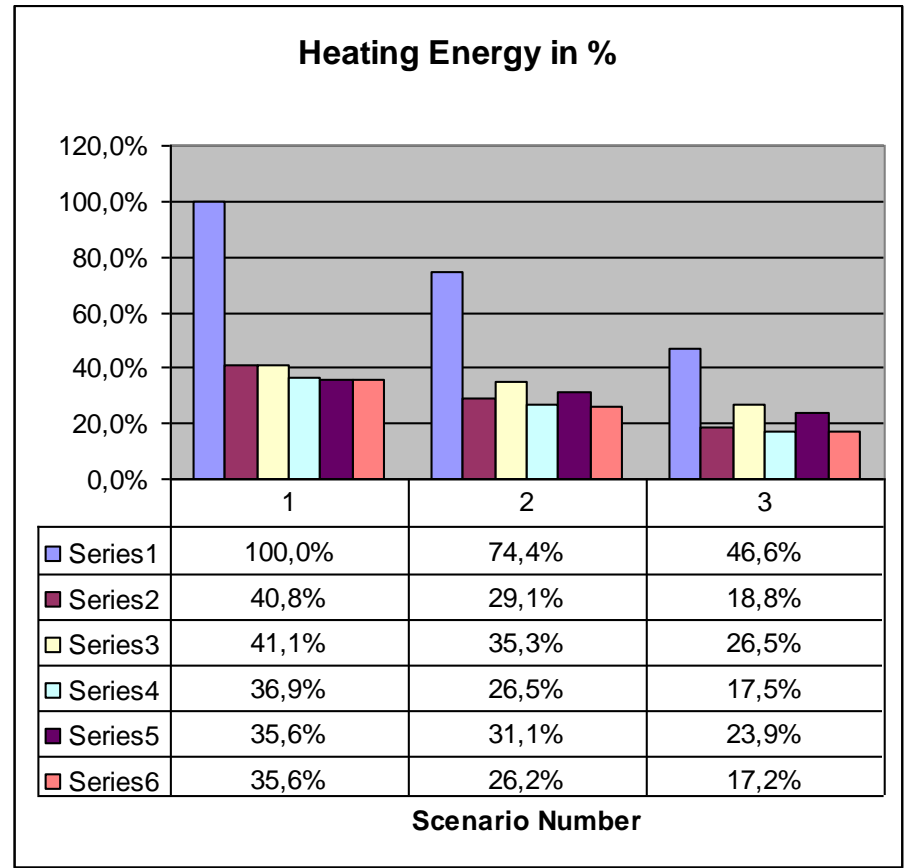

HOSP 3: Floor Insulation and Ventilation Control

We investigate in the following the possibilities of using:

- a removable insulation on the floor in contact with the earth (e.g. carpet with a plastic grid) corresponding to an EPS thickness of 1 $\mathrm{cm}$ and

- a ventilation control reducing $n$ during the night from $n=0.6$ (day) to $n=0.1$ (night)

The above investigations are limited to the Series 2 and Series 3 cases ( 5 $\mathrm{cm}$ outer or inner insulation), while the retrofitting series $4-6(10 \mathrm{~cm}$ insulation) are left for further possible investigations. The following Series 7 Series 10 are thermally analyzed (Table 2)

Table 2. Retrofitting Series 7-10

\begin{tabular}{|c|l|}
\hline Series 7 & $\begin{array}{l}\text { Building with inner EPS insulation } 5 \mathrm{~cm} \text { of walls and roof and with } \\
1 \mathrm{~cm} \text { EPS removable insulation on the floor (e.g. carpet) }\end{array}$ \\
\hline Series8 8 & $\begin{array}{l}\text { Building with inner EPS insulation } 5 \mathrm{~cm} \text { of walls and roof, with } \\
1 \mathrm{~cm} \text { EPS removable insulation on the floor (e.g. carpet) and with } \\
\text { ventilation control }\end{array}$ \\
\hline Series 9 & $\begin{array}{l}\text { Building with inner EPS insulation } 5 \mathrm{~cm} \text { of walls and roof and with } \\
1 \mathrm{~cm} \text { EPS removable insulation on the floor (e.g. carpet) }\end{array}$ \\
\hline Series10 & $\begin{array}{l}\text { Building with inner EPS insulation } 5 \mathrm{~cm} \text { of walls and roof, with } \\
\text { 1cm EPS removable insulation on the floor (e.g. carpet) and with } \\
\text { ventilation control }\end{array}$ \\
\hline
\end{tabular}


The results of the heating energy simulations for Scenarios $7-10$ are shown in Fig. 7 (Scenario 1 - Series 1 corresponds to 100\%). We observe that a further reduction of the heating energy can be achieved. For the inner insulation case (Series2) this reduction amounts for Scenario3 6.7\% (from $18.8 \%$ to $12.1 \%$ ), while for the outer insulation case (Series3) the relevant reduction is equal to $7.5 \%$ (from $26.5 \%$ to $19.0 \%$ ). If the analyses stop at this point, it is clear that the choice of a retrofitting scenario depends now on time and costs for the realization of the above retrofitting measures.

Figure 7. Heating Energy per day in \% for Retrofitting Series 7-8 and Scenarios 1-3

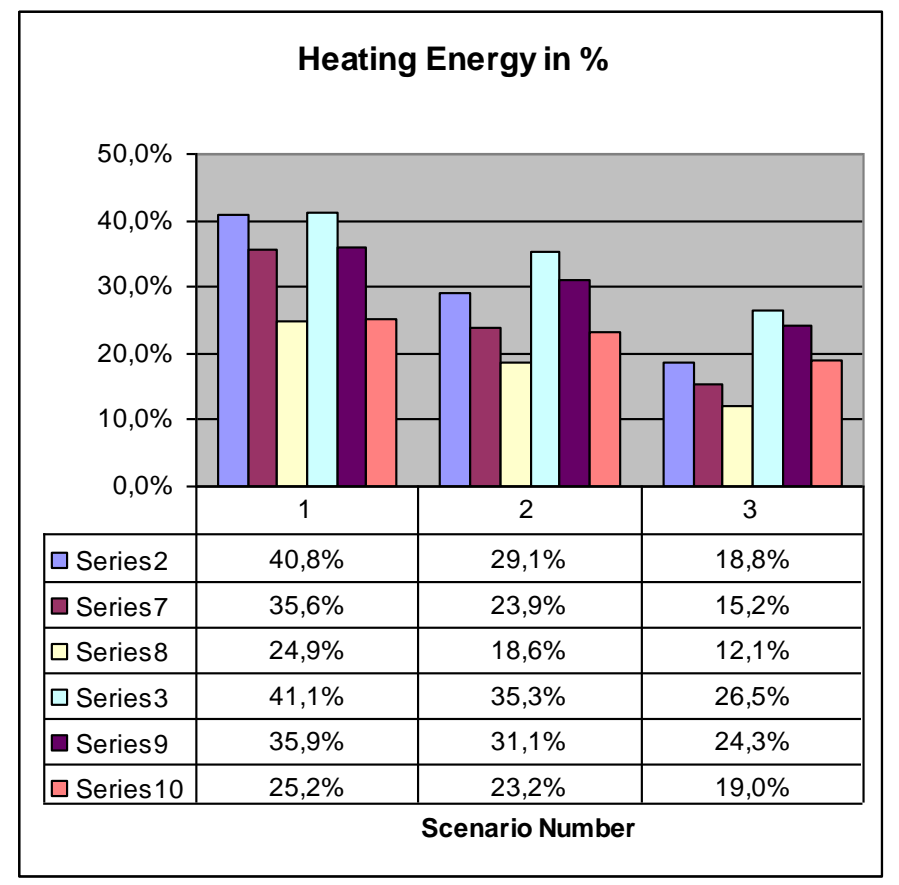

HOSP 4: Transient Response of the Building from an Unheated to a Heated $\underline{\text { Period }}$

An interesting aspect for the choice of retrofitting measures is the transient thermal response of the building from an unheated to a heated period. This is the case when the heating system is not in use for a certain time (over the weekend, during absence for a trip, etc.). In the following we will show simulation results for $\mathrm{Ds}=1$, with the initial conditions for the floor equal to the earth temperature and the initial conditions for the other building components equal to the mean temperature of the environment. As we may see from Fig. 8 more heating energy is necessary in the case of outer insulation (Series10) than in the inner insulation case (Series 8). This is due to the higher inner thermal mass of Series 10 involved in the heating process of the building. 
Figure 8. Simulation Results for the Instationary Behavior of the Heating Scenario 3 for the Series 8 and 10

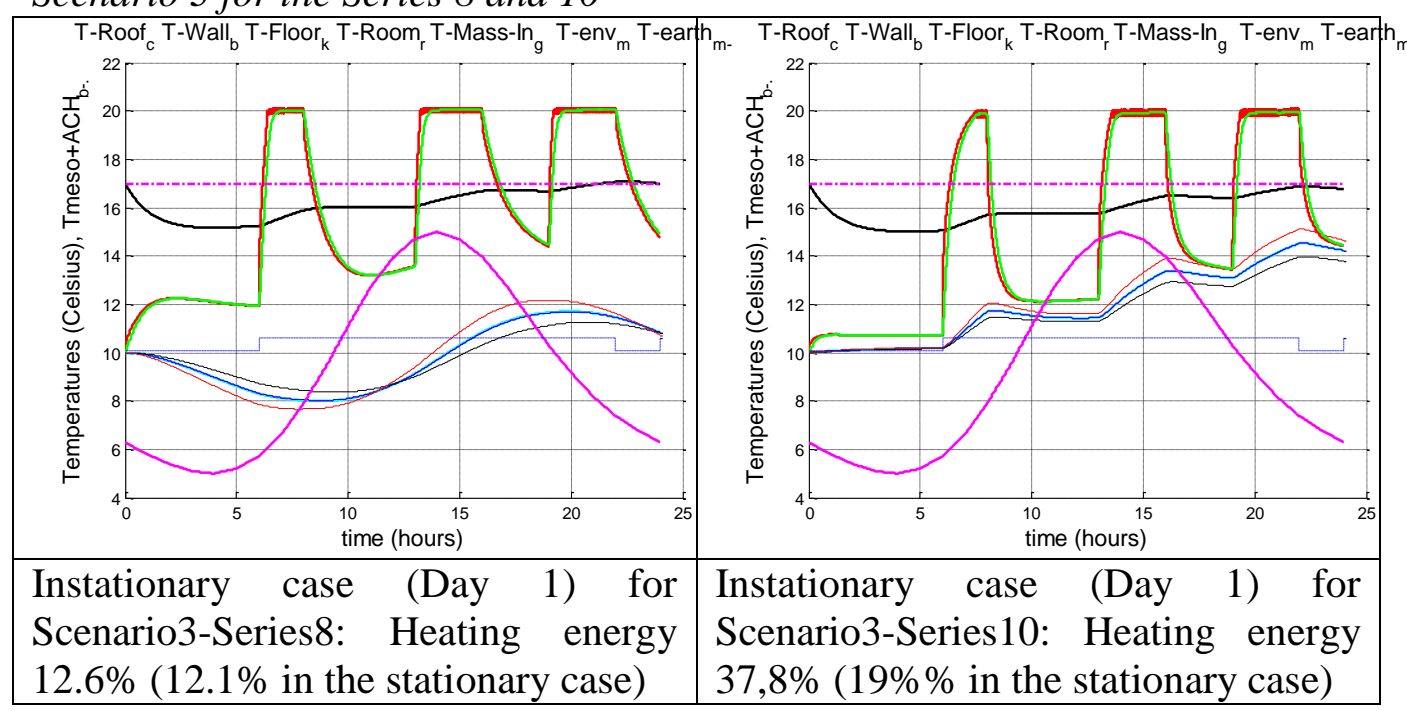

HOSP 5: Sensitivity of Thermal Analysis to Inner Mass Assumptions

The input data of a thermal analysis is many times difficult to determine with the necessary accuracy. In this category fall e.g. ventilation, inner mass, thermal bridges, etc. if the building (or house) has a complex interior consisting of rooms, corridors, walls, doors, furniture, etc. In such cases a sensitivity analysis becomes necessary.

As an example we present in the following a sensitivity analysis (Series 11 - 14) for the Series 2 and Series 3 cases concerning the variation of the inner mass (Table 3). Scenario1-Series 1 corresponds to $100 \%$.

Table 3. Variation of the Inner Mass for the Series 2 and Series 3 Cases

\begin{tabular}{|l|l|}
\hline Series 11 & $\begin{array}{l}\text { Building with inner EPS insulation } 5 \mathrm{~cm} \text { of walls and roof and (Series2) } \\
\text { but with 2 x greater inner mass }\end{array}$ \\
\hline Series12 & $\begin{array}{l}\text { Building with inner EPS insulation } 5 \mathrm{~cm} \text { of walls and roof and ( Series2) } \\
\text { but with 5 x greater inner mass }\end{array}$ \\
\hline Series 13 & $\begin{array}{l}\text { Building with outer EPS insulation } 5 \mathrm{~cm} \text { of walls and roof and ( Series3) } \\
\text { but with 2 x greater inner mass }\end{array}$ \\
\hline Series14 & $\begin{array}{l}\text { Building with outer EPS insulation } 5 \mathrm{~cm} \text { of walls and roof and ( Series3) } \\
\text { but with 5 x greater inner mass }\end{array}$ \\
\hline
\end{tabular}

The simulation results are shown in Fig. 9. In all cases the increase of the inner mass leads to an increase of the heating energy. The increase is as expected very small for Scenario 1 ( $24 \mathrm{~h}$ heating) but not for the other two Scenarios (heating 6:00-22:00 and discontinuous heating 6:00-8:00, 13:0016:00 and 19:00-22:00). Again as expected, the influence of the inner mass is greater in case of inner insulation (Series 11, 12) than in case of outer insulation (Series 13, 14). 
However even for a $5 \mathrm{x}$ greater inner mass, we notice that the sensitivity of the heating energy is relatively small, and this increases the reliability of the up to now thermal analyses results.

Figure 9. Simulation Results for a Variation of the Inner Mass for the Series 2 and Series 3 Cases

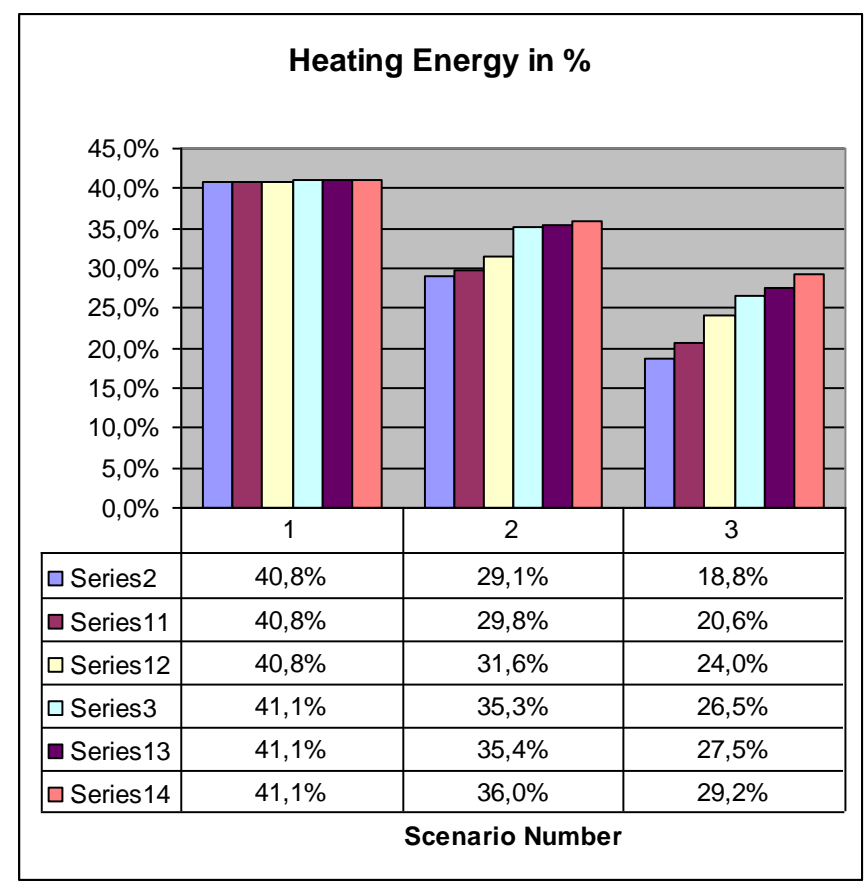

\section{Concluding Remarks}

The above analysis according to the Hierarchical Optimization method makes clear that retrofitting optimization represents, even for the case of the minimization of the thermal needs (here shown only for winter), a complex procedure. It makes necessary the navigation on the surface of a rugged landscape, which is the optimization function, and the decision making process is a multi-step and multi-criteria process. This navigation can not be successfully performed without engineer's knowledge and expertise, as it is shown above.

\section{Conclusion}

In this paper, we present a method for the retrofitting optimization of buildings based on Hierarchical Optimization. The proposed method disrupts the global optimization problem into a number of local optimization problems/search procedures, which can be successfully defined if engineer's knowledge and expertise are considered. The method is introduced in a general manner including the analysis of the so called principal components, but the case study refers only to the minimization of the heating energy in winter and only for one weather scenario. The case study is not complete in the sense that 
it does not include all possible aspects of retrofitting, but it is indicative for the way the method has to be applied. Very important is also that the case study succeeds to show that the decision making process is a multi-step and multicriteria process which needs engineer's knowledge and expertise and which can not be easily transformed in a global optimization problem in the sense of a mathematization logic.

Acknowledgement: This work was financed by a research grant from the Research Promotion Foundation of Cyprus under contract ERACOBUILDVDP/0609/02 entitled "A concept for promotion of sustainable retrofitting and renovation in early stages (ACES)".

\section{References}

[1] R. Zeng, X. Wang, H. Di, F. Jiang, Y. Zhang (2011). 'New concepts and approach for developing energy efficient buildings: Ideal specific heat for building internal thermal mass'. Energy and Buildings 43: 1081-1090.

[2] N. Djuric, V. Novakovic (2012). ' Identifying important variables of energy use in low energy office building by using multivariate analysis'.Energy and Buildings 45: 91-98.

[3] F. Chlela, A. Husaunndee, C. Inard, P. Riederer (2009). 'A new methodology for the design of low energy buildings'. Energy and Buildings 41: 982-990.

[4] S. Petersen, S. Svendsen (2012). 'Method for component-based economical optimization for use in design of new low-energy buildings'. Renewable Energy 38: $173-180$.

[5] M. Fesanghary, S. Asadi, Z. W. Geem (2012). 'Design of low-emission and energy-efficient residential buildings using a multi-objective optimization algorithm'. Building and Environment 49: 245-250.

[6] Giovanni Zemella, D. DeMarch, M. Borrottid, I. Poli (2011). 'Optimised design of energy efficient building via Evolutionary Neural Networks'. Energy and Buildings 43: 3297-3302.

[7] D. Tuhus-Dubrow, M. Krarti (2010). 'Genetic-algorithm based approach to optimize building envelope design for residential buildings'. Building and Environment 45: 1574-1581.

[8] F. Chlela, A. Husaunndee, C. Inard, P. Riederer (2009). 'A new methodology for the design of low energy buildings'. Energy and Buildings 41: 982-990.

[9] R. Zeng, X. Wang, H. Di, F. Jiang, Y. Zhang (2011). 'New concepts and approach for developing energy efficient buildings: Ideal specific heat for building internal thermal mass'. Energy and Buildings 43: 1081-1090.

[10] N. Djuric, V. Novakovic (2012). 'Identifying important variables of energy use in low energy office building by using multivariate analysis'. Energy and Buildings 45: 91-98.

[11] M. Bhandari, S. Shrestha, J. New (2012). 'Evaluation of weather datasets for building energy simulation'. Energy Buildings: doi:10.1016/j.enbuild.2012.01. 033.

[12] Richard Cantin, Andrea Kindinis, Pierre Michel (2012). 'New approaches for overcoming the complexity of future buildings impacted by new energy constraints'. Futures 44: 735-745. 
[13] S. Attia, E. Gratia, A. De Herde, Jan L.M. Hensen (2012). 'Simulation-based decision support tool for early stages of zero-energy building design'. Energy Buildings: doi:10.1016/j.enbuild.2012.01.028.

[14] Z. Yu, B. Fung, F. Haghighat, H. Yoshino, E. Morofsky (2011). 'A systematic procedure to study the influence of occupant behavior on building energy consumption'. Energy and Buildings 43: 1409-1417.

[15] O. Santin (2011). 'Behavioural patterns and user profiles related to energy consumption for heating'. Energy and Buildings 43: 2662-2672.

[16] D. Saelens, W. Parys, R. Baetens (2011). 'Energy and comfort performance of thermally activated building systems including occupant behavior'. Building and Environment 46: 835-848.

[17] F. Oldewurtel, A. Parisio, C. Jones, D. Gyalistras, M. Gwerder, V. Stauch, B. Lehmann, M. Morari (2012). 'Use of model predictive control and weather forecasts for energy efficient building climate control'. Energy and Buildings 45: $15-27$.

[18] M. Wallace, R. McBride, S. Aumi, P. Mhaskar, J. House, T. Salsbury (2012). 'Energy efficient model predictive building temperature control'. Chemical Engineering Science 69: 45-58.

[19] S. Karjalainen, V. Lappalainen (2011). 'Integrated control and user interfaces for a space'. Building and Environment 46: 938-944.

[20] E. Asadi, M. Gameiro da Silva, C. Henggeler Antunes, L. Dias (2012). 'Multiobjective optimization model for building retrofit strategies'. Fifth National Conference of IBPSA-USA, Madison, Wisconsin.

[21] J. Bracken and J.M. McGill (1974). 'A Method for Solving Mathematical Programs with Nonlinear Programs in the Constraints'. Operations Research 22: 1097-1101

[22] B. Colson, P. Marcotte, G. Savard (2007). 'An overview of bilevel optimization'. Ann Oper Res153: 235-256.

[23] K.S. Leung, I. King, Y.B. Wong (2006). 'A probabilistic cooperative-competitive hierarchical model for global optimization'. Applied Mathematics and Computation 175: 1092-1124. 
